\title{
RELIGIÃO NA LITERATURA DE CORDEL ANÁLISE DA RELIGIOSIDADE POPULAR DO NOR- DESTE BRASILEIRO
}

\author{
Prof. Dr. Carlos Ribeiro Caldas Filho
}

\begin{abstract}
RESUMO
Partindo do pressuposto teórico básico que há um valor epistemológico na literatura para o estudo tanto da teologia como também da religião, o presente artigo tem objetivo de apresentar qual é a visão religiosa veiculada pela literatura popular nordestina conhecida como "literatura de cordel". Ao mesmo tempo, apresenta que conteúdos teológicos são expressos pela citada literatura.
\end{abstract}

Palavras-Chave: Religião e literatura, literatura popular, religiosidade popular.

\section{ABSTRACT}

The present essay has as its basic theoretical presupposition that there is an epistemological value in literature, in order to study theology and religion as well. Therefore, the goal of this essay is to present the religious and theological elements that can be found in folk literature of Brazilian Northeast. Besides, this essay intends to present also the theological contents of this folk literature, known as "literatura de cordel".

Key Words: Religion and literature, folk literature, folk religiosity

INTRODUÇÃO 
Recentemente em muitos círculos acadêmicos, no Brasil e em diversos outros países, tem sido crescente o interesse na pesquisa na interface religião-literatura (e também teologia-literatura). Em tempos ditos pós-modernos disciplinas ligadas ao estudo da literatura ocupam lugar de destaque na academia. De fato, estudos de crítica literária e de literatura comparada têm enriquecido pesquisas sobre diferentes possibilidades do fenômeno religioso. Até pouquíssimo tempo atrás, quase que só se estudava religião no Brasil com auxílio de ferramentas sociológicas. Portanto a academia brasileira é pródiga em textos que usam Max Weber como referencial teórico de suas pesquisas. A "descoberta" do valor epistemológico da literatura para o estudo da religião tem produzido uma lufada de ar fresco no estudo acadêmico do fenômeno religioso no Brasil. Portanto, respeitadas escolas e centros de pesquisa em teologia e em ciência(s) da religião, no Brasil e no mundo estão levando cada vez mais a sério esta interface, a um ponto tal que já é cada vez menor o número de unidades de ensino onde há cursos de teologia e/ou de religião que ainda estão na "velha guarda", presas à perspectiva única de abordagem do fenômeno religioso somente com ferramentas de análise sociológica.

Neste sentido, o presente texto procura apresentar um estudo de um determinado aspecto da religiosidade popular brasileira, conforme veiculada por um elemento da literatura popular do país. A proposta do presente trabalho parte de uma hipótese algo óbvia, qual seja: a cultura popular nordestina tem na religiosidade um de seus eixos centrais, e através da veiculação da literatura popular conhecida como literatura de cordel é possível examinar elementos desta religiosidade. O cordel veicula uma autêntica "teologia popular", em versos. Este fato já fora observado, praticamente trinta anos atrás, por Araújo (1974, p. 41). Isto é coerente com o aspecto "popular" e tradicional da literatura de cordel, literatura do povo para o povo, que apresenta a espontaneidade com que o povo reflete sobre vários aspectos da vida (cf. Araújo, 1973, p. 171). Por oportuno, observe-se que a religiosidade popular nordestina é por demais abrangente. De modo que não se pretende aqui advogar uma redução, como se a literatura de cordel sintetizasse toda a religiosidade popular do Nordeste do Brasil.

Não se entrará aqui em um detalhamento técnico, isto é, em perspectiva da teoria literária, da história da literatura ou da crítica literária, da literatura de cordel propriamente. Tal detalhamento fugiria ao escopo deste

66 ReVIStA de Cultura TeOlógICA - V. 13 - N. 52 - JUL/SET 2005 
trabalho ${ }^{1}$. Também deve ser deixado claro que não se pretende aqui em um ensaio "explicar" exaustivamente toda a complexidade e densidade deste interessante aspecto da nossa cultura, tentação contra a qual Vannucchi (1999, p. 49-53) com propriedade adverte. Por oportuno, registra-se apenas a dificuldade em encontrar fontes acadêmicas que tratem da temática da literatura de cordel. Uma pesquisa em livrarias acadêmicas de médio e grande porte revela o virtual desprezo que a literatura popular tem recebido no Brasil por parte de estudiosos de literatura. Curiosamente, estrangeiros, como o brasilianista estadunidense Mark Curran (1973) e o holandês Joseph Luyten (1983) têm se debruçado sobre a literatura popular nordestina mais que alguns brasileiros. Ainda que não seja, como acaba de ser afirmado, propósito deste texto apresentar aspectos técnicos da literatura de cordel, é oportuno apresentar o que a respeito do cordel o cordelista Rodolfo Coelho Cavalcante escreveu:

Cordel quer dizer barbante

Ou senão mesmo cordão

Mas cordel-literatura

É a real expressão

Como fonte de cultura

Ou melhor poesia pura

Dos poetas do sertão

Na França, também na Espanha

Era nas bancas vendida

Que fosse em prosa ou em verso

Por ser a mais preferida

Com o seu preço popular

Poderia se encontrar

Nas esquinas da avenida

Era um pequeno volume

A edição publicada

Tamanho 15 por 12

Pra ser melhor consultada

sso no século XVIII

\footnotetext{
${ }^{1}$ Para detalhes técnicos, consultar, inter alia, Cascudo (1984, p. 339).
} 
Depois de noventa e oito

Foi aos poucos desprezada

No Brasil é diferente

O cordel-literatura

Tem que ser todo rimado

Com sua própria estrutura

Versificado em sextilhas

Ou senão em setilhas

Com a métrica mais pura ...

(Origem da literatura de cordel e a sua expressão de cultura nas letras de nosso povo)

O alvo deste texto é apresentar, posto que em síntese, a "religião de cordel", isto é, a religiosidade conforme entendida e interpretada pelos cordelistas nordestinos. O método de pesquisa adotado é o bibliográfico, restrito aos cordéis que tratam de temáticas propriamente religiosas. Portanto, nesta pesquisa desprezaram-se vertentes interessantíssimas da literatura popular nordestina, como os cordéis de fundo político como O prefeito que foi pegado com a boca na botija, Carlos Lacerda e suas diabruras, A capacidade do General Lott e Sururu na Prefeitura (todos de José Gomes, o legendário Cuíca de Santo Amaro), clássicos como O pavão misterioso, de José Camelo de Melo Rezende (talvez o mais famoso de todos os cordéis nordestinos) e os de temáticas de realismo fantástico (gênero literário do qual é mais que abundante a literatura latino-americana) como o best seller de Rodolfo Coelho Cavalcante (um dos maiores cordelistas de todos os tempos) intitulado $A$ moça que bateu na mãe e virou cachorra (que vendeu mais de um milhão de exemplares - este cordel curiosamente foi seguido de uma continuação: O desencanto da moça que bateu na mãe e virou cachorra).

A partir de um exame, evidentemente limitado às fontes primárias às quais o autor teve acesso, constatam-se alguns pontos básicos para a descrição da religiosidade popular nordestina. Apresentar-se-ão a seguir estes pontos, que visam descrever a cosmovisão (Weltauschauung) religiosa popular do nordeste do Brasil. O ser humano nordestino, não raro simples e pobre, com pouca (quiçá pouquíssima, ou mesmo nenhuma) instrução formal, vive em um mundo encantado, em que as barreiras e fronteiras entre os universos material e espiritual não são muito nítidas. É um mundo povoado

68 Revista de Cultura TeOlógica - v. 13 - N. 52 - JUL/SET 2005 
por rico imaginário religioso, de fundo tradicionalmente cristão. Quanto a isso, pode-se afirmar:

Visão fechada e determinada da vida - A religiosidade popular brasileira, de raiz lusitana é indubitavelmente fatalista: o que acontece é porque já estava determinado a acontecer. Decerto este fatalismo do cristianismo popular lusitano transplantado para o Brasil tem explicação em influência recebida da presença islâmica de séculos na Península Ibérica. Com graça e singeleza Rodolfo Coelho Cavalcante indica a visão fatalista presente na cosmovisão religiosa popular nordestina em seu curioso cordel intitulado $O$ boi que falou no Piauí, quando apresenta uma mui curiosa conversa entre animais de criação de uma fazenda, na qual reclamam de sua triste sorte:

Disse o carneiro: - eu também

Morrerei assassinado

Porém é lei do destino

Para isso fui gerado

Quando chegar o meu dia

Mesmo sofrendo agonia

Terei que morrer calado...

Chegando aos pés do Cruzeiro

O boi para o céu falou:

- Desejo morrer agora

Como Deus determinou

Mesmo sem dizer um ai,

Muito obrigado meu Pai! -

E pra fazenda voltou...

O mesmo poeta com rasgos de erudição e sensibilidade filosófica apresenta uma visão fechada e determinada da vida em Tudo na terra tem fim, quando afirma:

Tudo na terra tem fim

É a pura realidade

Mas depois do fim começa

A vida-continuidade

Se um volta o outro fica

É assim que se explica 
A Lei de Deus em verdade.

Sentimento antiprotestante - A religiosidade popular nordestina é de matriz ibérica, romana pré-conciliar, herdeira direta do catolicismo popular português. É o que com propriedade José Comblin, em sua leitura sociológica do catolicismo latino-americano chama exata e simplesmente de "catolicismo popular" (apud Lepargneur, 1974, p. 61). Esta religiosidade é, em linhas geral, resistente ao movimento de abertura ecumênica inspirado por João XXIII no Vaticano II, e, portanto, notadamente antiprotestante. Alguns cordéis expressam com eloqüência este sentimento antiprotestante. Seus títulos chegam a ser hilários, como os seguintes: O protestante que virou urubu porque quis matar Frei Damião, O crente que vivia com uma jumenta em Xorozinho - CE (este "crente" é na verdade um adventista do sétimo dia, confundido pelo cordelista com um evangélico, equívoco aliás, assaz comum) $O$ encontro da crente que virou besta com o crente que virou jumento (ambos por duvidarem dos poderes do Padre Cícero). O cordel anônimo Aviso dos católicos contra os protestantes tem já no seu título um tom beligerante e polemista. Entretanto, há cordéis que apresentam uma visão mais simpática do protestantismo. É o caso de Discussão de um crente com um cachaceiro, de Vicente Vitorino.

Rejeição de uma religiosidade explicitamente não cristã - Apesar do catolicismo romano popular no Brasil ter, em geral, abertura para um sincretismo religioso (as famosas benzedeiras são prova eloqüente deste sincretismo na prática), há cordéis que explicitamente rejeitam religiosidades não cristãs. Abraão Batista deixa isso claro em $A$ macumbeira que foi fazer um despacho e despachou-se. Com contundência e de maneira bastante severa e agressiva, o poeta afirma:

No Crato tinha uma velha

Conhecida macumbeira

Possuía ajudantes

Para a sua maneira

E nos despachos cobrava

Mas do ganho sobrava

Pra fazer uma só feira

O dinheiro que ganhava

Daquela vil profissão

70 ReVista de Cultura TeOlógica - v. 13 - N. 52 - JUL/SET 2005 
Não dava pra quase nada

Só restava confusão

Pensava que tinha tudo

Mas ao leitor não iludo

- - era dinheiro do cão

Mesmo assim a macumbeira

Tinha grande freguesia

Os católicos vira-latas

Ela mesma os possuía

O que a velha ganhava

Depressa ela gastava

Como uma pobre vadia.

Resgate de temas bíblicos - $\mathrm{O}$ "catolicismo popular" tem reconhecidamente escassa base bíblica. Não obstante, alguns (poucos) cordéis apresentam de maneira didática e plena de criatividade, um resgate de alguns temas bíblicos. A imaginação encontrada em cordéis que apresentam personagens bíblicos é tanta que impressiona, ao acrescentar detalhes que não aparecem no texto bíblico propriamente. Pode-se também dizer que os cordéis que tratam do resgate de temas bíblicos constituem-se na versão oral e popular da representação de cenas bíblicas em vitrais e quadros, encontrados com freqüência em templos católico-romanos, antiga tradição da arte pictórica de influência cristã que visava ser a "Bíblia dos analfabetos". Via de regra são cordéis que apresentam narrativas sobre personagens bíblicos. Clássico deste tipo de cordel é Dimas, o bom ladrão, de João Martins de Ataíde. Outros que se enquadram nesta classificação são Os Dez Mandamentos e a vida de Moisés, do cordelista de Pernambuco João José da Silva, e Os sofrimentos de Cristo, de José Pacheco, conterrâneo de João José da Silva. Vez há em que uma narrativa em forma de cordel sobre personagem bíblico é apresentada de maneira totalmente divorciada do texto bíblico, como em Jesus, Pedro e o ferreiro da maldição, de Francisco Sales Areda e O grande debate de Lampeão com São Pedro, de José Pacheco.

Super ênfase em representantes do sagrado - É interessante por demais observar que há mais cordéis que apresentam temáticas religiosas sobre alguns personagens extremamente populares na cultura nordestina, que em personagens bíblicos propriamente. Tais personagens são representantes do sagrado entre o povo. São, vias de regra, clérigos, ou, em alguns 
casos, personagens do hagiográfico romano. Dentre cordéis que narram a respeito de personagens do hagiográfico, podem-se citar As sete espadas de dores da Santa Virgem Maria (de João José da Silva) e O poder de São Bartolomeu. Dentre estes, Frei Damião e o Padre Cícero Romão Batista, o "Padim Ciço" (ou "Padim Padi Ciço") estão entre os mais freqüentemente encontrados. O já citado Joseph Luyten, especialista em literatura popular, contabiliza cerca de trezentos cordéis a respeito de cada um destes dois religiosos (Luyten, 1983, p. 43). Quanto a isso, observe-se o que afirmou o conhecido folclorista Luis da Câmara Cascudo: "os homens que se tornam famosos pela sua santidade, inteligência, para o bem ou para o mal, são outros centos irradiantes de lendas, ampliações e deformações de fatos verossímeis, vistos através do ódio ou do amor popular" (1984, p. 366). Observa-se que o cordelista José Costa Leite escreveu a respeito destes dois religiosos: A carta misteriosa do Padre Cícero Romão e A voz de Frei Damião. O mesmo faz o poeta popular Apolônio Alves dos Santos, autor de O homem que virou bode por zombar de Frei Damião e Nascimento, vida e morte do Padre Cícero Romão. Este mesmo autor escreveu Adeus a Frei Damião 1898-1997 e Os sinais do fim do mundo que Padre Cícero dizia. Em Adeus a Frei Damião, o poeta aponta para supostas faculdades sobrenaturais do religioso italiano radicado no Brasil:

Muita gente até dizia

Que Frade Frei Damião

Andava muito ligeiro

Em frente da procissão

Teve alguém que observava

Que o Frade caminhava

Com os pés altos do chão.

O Padre Cícero Romão Batista é ainda mais citado que Frei Damião. Dentre tantos cordéis sobre o clérigo brasileiro, é possível citar, inter alia, Palavras do Padre Cícero sobre a guerra nuclear (João José da Silva), História da Guerra de Juazeiro do Padre Cícero Romão Batista em 1914 (Antonio Américo de Medeiros), A festa do monumento ao Padre Cícero Romão (José Bernardo da Silva) e Juazeiro está chamando todos os romeiros no dia 2 de Novembro (José Amaro Pereira). A super ênfase no Padre Cícero é coerente com o culto criado em torno deste religioso. Gunther Paulo Suess, teólogo católico alemão radicado no Brasil, em seu estudo sobre o catolicismo popular brasileiro, afirma que, em algumas regiões do nordeste, o Padre Cícero foi

72 ReVista de Cultura TeOlógica - v. 13 - N. 52 - JUL/SET 2005 
na prática elevado à condição de pessoa da Trindade (Suess, 1979, p. 68). Assim, nesta vertente da religiosidade popular brasileira, já não mais seria a Santíssima Trindade, mas uma reconfiguração em forma do "Santíssimo Quadrilátero": o Pai, o Filho, o Espírito Santo e o Padre Cícero. Ou então, continuaria a Trindade, mas formada pelo Pai, o Padre Cícero e a Virgem Maria. Uma leitura destes cordéis revela como o Padre Cícero tornou-se o intercessor por excelência do povo pobre e sofrido, efetivamente mais presente na vida do povo que o próprio Jesus Cristo. A exaltação da figura do Padre Cícero acima da pessoa de Jesus é evidente em Juazeiro está chamando todos os romeiros:

...Será no Horto encantado

Dia de festa e de luz

Meu padrinho lá está

Com seus olhinhos azuis

Todo vestido de branco

Fazendo a vez de Jesus...

Nesta mesma linha de raciocínio há que se mencionar a freqüência de cordéis que apresentam não um personagem do sagrado strictu senso, mas aquele que provavelmente é o mais conhecido e famoso da história e do imaginário nordestino. Trata-se evidentemente de Virgulino Ferreira da Silva, o Lampeão, apresentado em alguns cordéis em perspectiva religiosa. Não poucos cordéis apresentam Lampeão envolvido em uma questão de fundo religioso. Nesta categoria enquadram-se, entre tantos, Lampião e Maria Bonita tentados por Satanás, de Jota Barros, A briga de Antonio Silvino com Lampião no inferno, de José Costa Leite. Nesta linha, os mais curiosos talvez seja a trilogia de cordéis de autoria de José Pacheco: A chegado de Lampeão no inferno, A chegada de Lampeão no Purgatório e A chegada de Lampeão no céu. Quanto a Lampeão no inferno, José da Costa Leite em $O$ sanfoneiro que foi tocar no inferno diz:
... o inferno
é uma cidade asseada.
Lampião é o prefeito
E faz praça ajardinada
Está fazendo calçamento
E já tem água encanada
Até luz de Paulo Afonso 
Lampião já quer botar...

Em Lampião e a velha feiticeira (de José Cordeiro) o cangaceiro é retratado como herói tão poderoso que uma feiticeira querendo vingar-se dele, por haver deflorado sua filha, invoca o próprio Satanás, que envia demônios em forma de adolescentes negros ${ }^{2}$ para executar a pretendida vingança. Lampião e seu bando conseguem a tiros dispersar os demônios.

Quase ausência de Cristo - Sabe-se que o capítulo da teologia sistemática que se dedica ao estudo da pessoa e obra de Cristo é intitulado Cristologia. Uma abordagem da "cristologia do cordel" merece uma seção à parte neste estudo da religiosidade popular nordestina veiculada pela literatura de cordel. O primeiro ponto a se observar é a algo paradoxal quase ausência de Cristo no imaginário religioso popular do Nordeste do Brasil. Há mais cordéis que falam do diabo, o "cão", que sobre Jesus ${ }^{3}$. Isso reflete a ambientação existencial, a situação vivencial (Sitz im lebem) do habitante sofrido da zona rural, sujeito aos desmandos dos poderosos e às imprevisíveis e incontroláveis intempéries da natureza. Nada mais natural que procurar encontrar explicação para isso em um poderoso agente sobrenatural maligno. Há no entanto pelo menos uma exceção notável. Trata-se de $A$ mulher que foi surrada pelo diabo, de Rodolfo Cavalcante. Neste cordel, uma mulher, mãe de família, mas doidivanas, abandona o lar para gozar a vida, mas é advertida pelo próprio diabo que não deveria fazer o que pretendia. $\mathrm{Na}$ história, o diabo tem uma função mais de agente de Deus que de causador de males. Já se mencionou que há considerável número de cordéis que falam sobre personagens do hagiográfico romano tradicional ou de clérigos considerados clássicos representantes do sagrado, como Frei Damião e Padre Cícero. Fala-se mais nestes personagens que na pessoa de Cristo. Veja-se por exemplo o já citado cordel $A$ chegada de Lampeão no céu apresenta o herói no céu conversando com São Pedro, Santa Zulmira, São Panta, São Bernardo, São Ricardo, São Francisco da Penha, São Tomé, São Juvenil, São Moisés, Santa Jacinta, Santo Agostinho e São Francisco. Por incrível

\footnotetext{
${ }^{2} \mathrm{O}$ fato do cordel apresentar demônios em forma de adolescentes negros não se constitui em inequívoco sinal de racismo presente na cultura popular nordestina?

${ }^{3}$ Como (quase) sempre, os títulos dos cordéis apontam para o inusitado, o insólito e o inesperado. Veja-se o título deste cordel de Apolônio Alves dos Santos: O beberrão que lutou com o diabo na Sexta Feira da Paixão. Outro exemplo é Peleja de Riachão o Diabo, de José Bernardo da Silva.
}

74 ReVista de Cultura TeOlógica - v. 13 - N. 52 - JUL/SET 2005 
que pareça, não se menciona o nome de Cristo. Está presente por demais no imaginário religioso popular a idéia do Cristo flagelado e abandonado, sofrido e vencido, portanto, impotente para ajudar. No ocidente cristão, é de longa data a piedade em torno de Jesus crucificado. Esta piedade está presente na religiosidade popular brasileira. Um único exemplo proveniente da literatura popular da presença desta piedade tradicional na cultura brasileira é Cristo curando os fiéis em Porto das Caixas - Rio de Janeiro, do poeta paraibano Apolônio Alves dos Santos. Neste cordel, o poeta afirma:

Jesus quando andou no mundo

Cumprindo sua missão

Pregando e ensinando

A santa religião

Curou cegos e aleijados

Pela força da oração

E depois pelos judeus

Foi morto e crussificado (sic)

Mas prometeu ao mundo

Se fosse resssuscitado

Voltaria novamente

Porém sem ser esperado

Agora está constatado

Que Jesus está chamando

Dentro de Porto das Caixas

Muita gente está chegando

E centenas de fiéis

Jesus Cristo está curando...

Merece menção na elaboração do poeta uma ênfase que, conquanto popular, é ausente no texto bíblico, a saber: que Jesus voltaria novamente como crucificado. No também já citado As sete espadas de dores da Santa Virgem Maria o poeta popular pernambucano João José da Silva diz:

...Vendo Jesus Cristo morto

Ao pé da cruz se sentaram

5.000 e 5 chagas

Encontrou no corpo dele 
5.000 e doze espinhos

A Virgem retirou dele

5.000 gramas de sangue

Fazem cortina pra ele

As mãos estavam furadas

Os ossos desconjuntados

Despido de suas vestes

Os dois pés finos cravados

$O$ peito rasgado à lança

Os dois olhos fechados...

Observa-se que esta cristologia popular é marcada por um ideário de sofrimento, com forte ênfase na Paixão, e pouca ênfase na Ressurreição. Sendo assim, a cristologia veiculada pelo cordel brasileiro é coerente com e semelhante à cristologia popular ibérica, como observou com propriedade Juan Mackay em El otro Cristo Español (1993 [1933]), obra clássica a respeito. Tal ênfase é verdadeiramente secular no Brasil, pois o Catecismo do Padre Antonio Vieira não faz menção à Ressurreição. Portanto, um exame desta cristologia à luz do relato neo-testamentário revelará que falta à cristologia popular expressa nos cordéis nordestinos um equilíbrio que dê igual peso às narrativas da crucificação e da ressurreição de Jesus.

\section{CONCLUSÃO}

Como expresso no início deste texto, a religiosidade é elemento da mais elevada importância na mentalidade do povo nordestino. E a literatura popular expressa muito bem elementos do imaginário religioso popular. 0 que aqui se pretendeu apresentar não foi nada mais que uma introdução ao tema, intrigante, interessante e, por que não dizer, fascinante, mas, ainda não muito pesquisado por estudiosos do fenômeno religioso no Brasil. Espera-se que surjam outros estudos que retome o tema, e também estudos que pesquisem o fenômeno da religiosidade popular brasileira também a partir de outras manifestações artísticas do povo.

Prof. Dr. Carlos Ribeiro Caldas Filho

Doutor em Ciências da Religião pela Universidade Metodista de São Paulo. Docente da graduação em Teologia na Escola Superior de Teologia e

76 Revista de Cultura TeOlógica - v. 13 - N. 52 - JUL/SEt 2005 
do Programa de Pós-Graduação em Ciências da Religião da Universidade Presbiteriana Mackenzie, São Paulo.ccaldas@mackenzie.com.br

\section{BIBLIOGRAFIA}

AREDA, Francisco Sales. Jesus, Pedro e o ferreiro da maldição.

BARROS, Jota. Lampião e Maria Bonita tentados por Satanás.

BATISTA, Francisco das Chagas. Dimas, o bom ladrão.

BATISTA, Abraão. A macumbeira que foi fazer um despacho e despachou-se. CAVALCANTE, Rodolfo Coelho. Origem da literatura de cordel e a sua expressão de cultura nas letras de nosso país.

. O boi que falou no Piauí.

A mulher que foi surrada pelo Diabo.

O desencanto da moça que bateu na

mãe e virou cachorra.

CORDEIRO, José. Lampião e a velha feiticeira.

CUÍCA DE SANTO AMARO. O prefeito que foi pegado com a boca na botija. . Carlos Lacerda e suas diabruras,

. A voz de Frei Damião.

- A briga de Antonio Silvino com Lampião no inferno.

MEDEIROS, Antonio Américo de. História da Guerra de Juazeiro do Padre Cícero Romão Batista em 1914.

PACHECO, José. O grande debate de Lampeão com São Pedro. . A chegada de Lampeão no inferno.

A chegada de Lampeão no céu.

. Os sofrimentos de Cristo.

REZENDE, José Camelo de Melo. O pavão misterioso.

SANTOS, Apolônio Alves dos. Cristo curando os fiéis em Porto das Caixas - Rio de Janeiro.

SERAFIM, M. O protestante que virou um urubu porque quis matar Frei Damião. ARAÚJO, Alceu Maynard. Cultura popular brasileira. São Paulo: Melhoramentos, 1973

LEPARGNEUR, Hubert. Imagens de Cristo no catolicismo popular brasileiro. In: Quem é Jesus Cristo no Brasil? São Paulo: ASTE, 1974, p. 55-94.

LUYTEN, Joseph M. O que é literatura popular. São Paulo: Brasiliense, 1983 MACKAY, Juan. El otro Cristo Español. México, D.F.: Editorial Cupsa, 1993 [1933] SUESS, Catolicismo popular no Brasil. Tipologia e estratégia de uma religiosidade vivida. São Paulo, Loyola, 1979

VANNUCCHI, Aldo. Cultura brasileira. Sorocaba: Universidade de Sorocaba. São Paulo: Loyola, 1999 